- Special Lecture 1 -

\title{
Effect of Freezing on Structures and Chemical Constituents of Liver Tissue
}

\author{
Robert E. Stowell, M. D., Peter J. Goldblatt, Captain, USAF, MC, \\ Benjamin F. Trump, Captain, MC, USA, Charles C. Griffin \\ and Vaman S. Waravdekar, Ph. D.
}

Armed Forces Institute of Pathology, Washington, D.C., 20305

Slices of mouse liver were frozen on dry ice $\left(-79^{\circ} \mathrm{C}\right)$, in isopentane $\left(-155^{\circ} \mathrm{C}\right)$, or in propane $\left(-175^{\circ} \mathrm{C}\right)$. Some tissues were freeze-substituted without thawing to study the ice crystal artifacts; others were thawed for biochemical analysis of fixed for general structural or electron microscopic studies.

Light microscopic observations on tissues frozen on dry ice and freezesubstituted showed large ice crystals occupying the extracellar spaces including the sinusoids, in the cytoplasm and in the nuclei. Following thawing and fixation the tissue frozen on dry ice closely resembled the controls except for hyperchromatism of nuclei, smudging of celluar outlines and decrease in number of erythrocytes. Tissues frozen in isopentane and propane showed minute intracellular ice crystal artifacts in the frozen state and after thawing did not differ from tissues frozen on dry ice.

By electron microscopy of thawed liver, in tissue frozen on dry ice, and, to a lesser extent, in isopentane, the nuclear and cytoplasmic morphology was similar to control tissues except for the bile canaliculi and plasma membranes. After freezing with propane, there were substantial alterations in cytoplasmic organelles. Although there were some mitochondrial abnormalities aftar isopentane, after propane there were irregularities in shape, interruptions in continuity of membranes, pallor of matrix and absence of matrix granules. Of the single membrane limited inclusion bodies, only the microbodies showed change; the decrease in density of the matrix was most severe after propane cooling. The smooth surfaced endoplasmic reticulum was more suceptible to injury by freezing and thawing than the rough-surfaced component.

Biochemical measurements of succinoxidase showed losses of 26, 29 and $37 \%$ after freezing on dry ice or in isopentane and propane respectively. Losses of succinic dehydrogenase ranged from $11 \%$ on dry ice to $23 \%$ in propane. Changes in glutamic dehydrogenase appeared to reflect alterations in mitochondrial structure. Freezing or sonic treatment produced a 6-7-fold increase in glutamic dehydrogenase released from disrupted mitochondria. The nuclear enzyme NAD-pyrophosporylase was unaltered after freezing.

Thus after freezing of liver on dry ice, the large ice crystals produced the 
most displacement of cells and their gross constituents. After thawing, tissues frozen in propane showed the greatest chemical alterations associated with ultra-structural changes especially of the mitochondria, and dry ice the least chemical or structural changes. 